\title{
QRS Prolongation is Associated With High Defibrillation Thresholds During Cardioverter-Defibrillator Implantations in Patients With Hypertrophic Cardiomyopathy
}

\author{
Takayuki Nagai, MD; Takashi Kurita, MD; Kazuhiro Satomi, MD; Takashi Noda, MD; \\ Hideo Okamura, MD; Wataru Shimizu, MD; Kazuhiro Suyama, MD; \\ Naohiko Aihara, MD; Junjiro Kobayashi, MD*; Shiro Kamakura, MD
}

\begin{abstract}
Background: Although high defibrillation threshold (DFT) is a major and unavoidable clinical problem after implantation of an implantable cardioverter defibrillator (ICD), little is known about the cause and management of a high DFT in patients with hypertrophic cardiomyopathy (HCM). The purpose of this study was to assess the predictors of a high DFT in patients with HCM.

Methods and Results: Twenty-three patients with non-dilated HCM who underwent ICD implantation were included. The DFT at the time of the device implantation was measured in all patients. The patients were divided into 2 groups, a high DFT group (DFT $\geq 15 J, n=13$ ) and a low DFT group (DFT <15J, $n=10$ ); and their baseline characteristics were compared. The QRS duration was longer in the high than in the low DFT group (128 \pm 31 vs $103 \pm 12 \mathrm{~ms}$, respectively; $\mathrm{P}=0.02$ ). QRS duration, left ventricular (LV) end-systolic diameter, and LV ejection fraction were significant predictors of DFT in univariate analysis. However, in multivariate analysis, the only factor significantly associated with DFT was QRS duration $(\mathrm{P}=0.002)$.

Conclusions: QRS duration is the most consistent predictor of a high DFT in HCM patients undergoing ICD implantation. (Circ J 2009; 73: 1028-1032)
\end{abstract}

Key Words: Defibrillation threshold; Hypertrophic cardiomyopathy; Implantable cardioverter defibrillator; QRS prolongation

A

subgroup of patients with hypertrophic cardiomyopathy $(\mathrm{HCM})$ is at a high risk of having ventricular tachycardia and/or ventricular fibrillation. The implantable cardioverter-defibrillator (ICD) is widely recognized as the most effective and essential therapy for this patient population:-3 It has been demonstrated that both appropriate and inappropriate ICD discharges are frequently observed in HCM patients, ${ }^{1-3}$ and this might impair qualityof-life as well as reduce battery longevity. Class III antiarrhythmic agents such as amiodarone have the potential for reducing ICD shocks ${ }^{4}$ and might improve patients' prognosis. Furthermore, class I agents are also used in HCM patients to control atrial fibrillation or reduce the pressure gradient in the left ventricular (LV) outflow tract or midventricle when an obstruction is present $5^{5-7}$ The combined use of antiarrhythmic agents and an ICD in patients with $\mathrm{HCM}$, and the larger volume of myocardium (caused by hypertrophy of the left ventricle) might result in a high defibrillation threshold (DFT). However, the predictors of a high DFT in patients with HCM have not been fully characterized. Thus, the purpose of this retrospective study was

(Received July 31, 2008; revised manuscript received January 7 , 2009; accepted January 15, 2009; released online April 10, 2009) Division of Cardiology, Department of Internal Medicine, *Department of Cardiovascular Surgery, National Cardiovascular Center, Suita, Japan

Mailing address: Takashi Kurita, MD, Division of Cardiology, Department of Internal Medicine, National Cardiovascular Center, 5-7-1 Fujishiro-dai, Suita 565-8565, Japan. E-mail: kuritat@ hsp.ncvc.go.jp All rights are reserved to the Japanese Circulation Society. For permissions, please e-mail: cj@j-circ.or.jp to evaluate the factors causing a high DFT in patients with HCM and ventricular tachycardia/ventricular fibrillation.

\section{Methods}

\section{Study Subjects}

The study population consisted of 23 consecutive patients with an established diagnosis of HCM who underwent initial implantation of an ICD with a standard transvenous lead system at the National Cardiovascular Center from 1997 through to 2005. ICDs were implanted for secondary prevention in 20 of 23 patients, defined by clinical sustained ventricular tachyarrhythmia or resuscitation from sudden cardiac death. HCM was diagnosed on the basis of echocardiographic criteria defined as the presence of LV hypertrophy in the absence of other causes of hypertrophy. These patients also met the definition and classification proposed by the 1995 World Health Organization/International Society and Federation of Cardiology Task Force? All defibrillation leads were implanted by a left cephalic vein cutdown and positioned in the right ventricular apex. No patient had any prior pacemaker implantation, and 2 had permanent atrial fibrillation. Patients who were diagnosed with HCM who progressed to a dilated phase of HCM were excluded from the study.

\section{ICD Implantation and DFT Testing}

The following ICD models were implanted: $7220 \mathrm{C}(\mathrm{n}=$ 1), $7223 \mathrm{Cx}(\mathrm{n}=6), 7227 \mathrm{Cx}(\mathrm{n}=2), 7229 \mathrm{Cx}(\mathrm{n}=5), 7271 \mathrm{Cx}$ $(\mathrm{n}=1)$, and $7273 \mathrm{Cx}(\mathrm{n}=5)$, manufactured by Medtronic, Inc (Minneapolis, MN, USA); and the $1861(\mathrm{n}=3)$ manufac- 
Table 1. Patient Characteristics

\begin{tabular}{lccc}
\hline & \multicolumn{2}{c}{ Defibrillation threshold } & \multirow{2}{*}{ P value } \\
\cline { 2 - 3 } & $<15 \mathrm{~J}(\mathrm{n}=10)$ & $\geq 15 \mathrm{~J}(\mathrm{n}=13)$ & NS \\
\hline Gender (M/F) & $7 / 3$ & $9 / 4$ & NS \\
Age, years & $52 \pm 18$ & $54 \pm 16$ & NS \\
Height, cm & $163 \pm 8$ & $162 \pm 8$ & NS \\
Body weight, $\mathrm{kg}$ & $55 \pm 9$ & $59 \pm 7$ & 0.02 \\
QRS duration, ms & $103 \pm 12$ & $128 \pm 31$ & 0.09 \\
LV ejection fraction, $\%$ & $68 \pm 16$ & $58 \pm 10$ & 0.0001 \\
Defibrillation threshold, J & $10 \pm 0.4$ & $18 \pm 5$ & NS \\
Antiarrhythmic agents, $\mathrm{n}(\%)$ & $3(30)$ & $6(46)$ & $\mathrm{NS}$ \\
Amiodarone, $\mathrm{n}(\%)$ & $2(20)$ & $4(31)$ & NS \\
Disopyramide, $\mathrm{n}(\%)$ & $1(10)$ & $1(8)$ & NS \\
Mexiletine, $\mathrm{n}(\%)$ & $0(0)$ & $2(15)$ & $\mathrm{NS}$ \\
Single coil lead system, $\mathrm{n}(\%)$ & $9(90)$ & $8(62)$ & \\
\hline
\end{tabular}

Data are mean \pm SD.

NS, not significant; LV, left ventricular.

Table 2. Echocardiographic Measurements

\begin{tabular}{lccc}
\hline & \multicolumn{2}{c}{ Defibrillation threshold } & \multirow{2}{*}{ P value } \\
\cline { 2 - 3 } & $<15 \mathrm{~J}(\mathrm{n}=10)$ & $\geq 15 \mathrm{~J}(\mathrm{n}=13)$ & \\
\hline LV end-diastolic diameter, mm & $39 \pm 6$ & $42 \pm 6$ & $\mathrm{NS}$ \\
LV end-systolic diameter, mm & $22 \pm 6$ & $26 \pm 5$ & 0.048 \\
Interventricular septal thickness, $\mathrm{mm}$ & $17 \pm 5$ & $18 \pm 6$ & $\mathrm{NS}$ \\
LV posterior wall thickness, mm & $13 \pm 3$ & $14 \pm 8$ & $\mathrm{NS}$ \\
LV mass, $\mathrm{g}$ & $286 \pm 124$ & $369 \pm 211$ & $\mathrm{NS}$ \\
LV mass index, $\mathrm{g} / \mathrm{m}^{2}$ & $178 \pm 64$ & $227 \pm 126$ & $\mathrm{NS}$ \\
\hline
\end{tabular}

Data are mean \pm SD.

Abbreviations see in Table 1.

tured by Guidant Corp (St. Paul, MN, USA). All ICD systems used biphasic waveforms. A single-coil transvenous lead system was utilized in 17 patients and a dual-coil system was used in 6 patients. All implant procedures were performed under general anesthesia using propofol in the operating room. At the end of the ICD implantation after ventricular fibrillation was induced using a T-wave shock or $50-\mathrm{Hz}$ burst pacing, DFT was measured using a step-down method from an initial delivered energy of $15 \mathrm{~J}$ with decrements of $5 \mathrm{~J} 9,10$ If the initial $15 \mathrm{~J}$ shock failed, the energy was increased in 5J steps until defibrillation was successful. A 5-min interval was allowed between inductions and defibrillations of ventricular fibrillation. The DFT was defined as the lowest delivered energy shock that resulted in a successful defibrillation. According to the mean value of DFT $(14 \pm 5 \mathrm{~J})$, the patients were classified into 10 patients with a low DFT $(<15 \mathrm{~J})$ and 13 patients with a high DFT $(\geq 15 \mathrm{~J})$.

\section{Variables Assessed}

The following variables were used for analysis: sex, age, height, body weight, QRS duration, LV ejection fraction quantified by radionuclide ventriculography or LV cineangiography, the use of amiodarone or class I antiarrhythmic drugs, utilization of a single-coil transvenous lead system, echocardiographic parameters including the LV end-diastolic and end-systolic diameters, interventricular septal thickness, LV posterior wall thickness, LV mass calculated from echocardiographic data by standard formulas, 11,12 and LV mass index (dividing the LV mass by the body surface area). The QRS duration was defined as the maximal QRS length in any lead measured manually from the first to the last sharp deflection crossing the isoelectric line using standard resting 12-lead ECG (sweep speed, $25 \mathrm{~mm} / \mathrm{s}$ and
$1 \mathrm{mV} / \mathrm{cm}$ standardization). The average values of QRS duration that were obtained from 2 independent investigators blinded to each other's results were used (interobserver correlation for QRS duration was 0.941).

\section{Statistical Analysis}

The results are presented as percentages or the mean \pm SD, as appropriate. Several parameters in the 2 groups were compared with an unpaired Student's t-test. Categorical variables were compared using a Fisher's exact test. Linear regression analysis was used to determine the relationship between DFT and QRS duration. The variables with a P value $<0.10$ were entered into a multiple linear regression analysis to identify the independent predictors of DFT. The level of statistical significance was set at a $\mathrm{P}$ value $<0.05$.

\section{Results}

Twenty-three patients ( 16 men; mean age $53 \pm 17$ years, range 16-77 years) were included in the analysis. None of the patients had any extreme hypertrophy $(\geq 30 \mathrm{~mm})$, and 4 patients were found to have significant LV outflow obstruction $(\geq 30 \mathrm{mmHg})$ at rest by continuous Doppler echocardiography. The mean LV ejection fraction was $62 \pm 13 \%$. Indications for an ICD implantation were primary prevention in 3 patients, ventricular tachycardia in 4 patients and aborted sudden cardiac death in 16 patients. At the time of device implantation, 6 patients were being treated with amiodarone ( $200 \mathrm{mg} /$ day), 2 with sotalol and 4 with class I antiarrhythmic agents (disopyramide and mexiletine). No patient showed evidence of abnormalities in serum electrolyte concentrations and/or in acid-base equilibrium at the device implantation stage. 


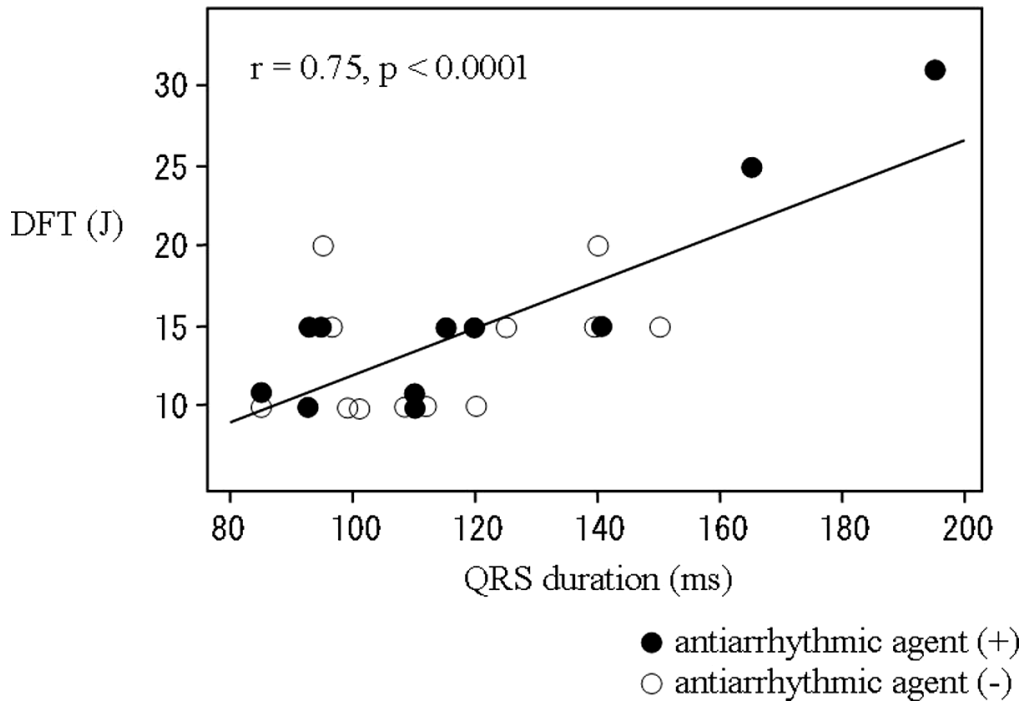

Figure. Relationship between QRS duration and DFT. The QRS duration demonstrated a modest positive correlation with the DFT at the time of the device implantation. DFT, defibrillation threshold.
The ICDs were implanted without any complications, and the induction and termination of the ventricular fibrillation were successful in all patients. The DFT (energy delivered) ranged from $10 \mathrm{~J}$ to $31 \mathrm{~J}$ (10 patients, $10-14 \mathrm{~J}$; 9 patients, $15-19 \mathrm{~J}$; 2 patients, 20-24J; 2 patients, 25-31J). The DFTs in patients treated with amiodarone (6 patients), combined amiodarone and a class I antiarrhythmic agent (mexiletine) (1 patient), class I antiarrhythmic agents (3 patients), and sotalol ( 2 patients) were $16 \pm 9 \mathrm{~J}, 15 \mathrm{~J}, 17 \pm 7 \mathrm{~J}$, and $13 \pm 3 \mathrm{~J}$, respectively. An unacceptably high DFT $(\geq 25 \mathrm{~J})$ was obtained in 2 patients who were receiving amiodarone ( 1 patient, $200 \mathrm{mg} /$ day) or mexiletine (1 patient, $450 \mathrm{mg} /$ day) at the time of the implantation (these 2 patients were included in the high DFT group). However, the DFT in these 2 patients decreased to a level with a 10J safety margin between the maximum shock energy of the ICD and the DFT after cessation of amiodarone (21J) or mexiletine (20J). Therefore, none of the patients required any additional use of a subcutaneous array or patch.

The baseline characteristics and echocardiographic measurements for the 2 groups are listed in Tables $\mathbf{1}$ and $\mathbf{2}$, respectively. The QRS duration was significantly longer in patients with a high than with a low DFT (128 \pm 31 vs $103 \pm$ $12 \mathrm{~ms}$, respectively; $\mathrm{P}=0.02$ ). There was a trend toward a lower LV ejection fraction in the patients with a high DFT $(\mathrm{P}=0.09)$. The use of amiodarone and/or class I antiarrhythmic drugs did not differ between the 2 groups. As shown in Table 2, the LV end-systolic diameter was significantly smaller in those patients with a low than with a high DFT ( $22 \pm 6$ vs $26 \pm 5 \mathrm{~mm}$, respectively; $\mathrm{P}=0.048$ ). The $\mathrm{LV}$ mass and mass index exhibited no statistically significant difference between the 2 groups.

The QRS duration demonstrated a modest positive correlation with the DFT at the time of device implantation ( $\mathrm{r}=$ $0.75, \mathrm{P}<0.0001$ ) for the group as a whole (Figure). A multivariate analysis was performed on the 3 variables that had a $P$ value $<0.10$ in the univariate analysis: $Q R S$ duration, $L V$ end-systolic diameter, and LV ejection fraction. This analysis showed that QRS duration was the only independent predictor of DFT $(\mathrm{P}=0.002)$.

\section{Discussion}

In this study, we identified QRS duration as the only variable that was associated with a high DFT at the time of ICD implantation in patients with HCM. To the best of our knowledge, this is the first report to investigate the association between QRS duration and DFT in patients with HCM. Because of the pro-arrhythmic and/or negative inotropic effects of class I antiarrhythmic agents, the use of these drugs in patients with depressed LV function is contraindicated. Furthermore, class Ia antiarrhythmic drugs such as disopyramide or cibenzoline might lead to a rise in DFT by producing a wider zone between the resting membrane potential and threshold potential! ${ }^{3}$ However, class Ia antiarrhythmic agents have been regarded as part of the standardized therapy, not only for reducing LV pressure gradients ${ }^{5-7}$ in patients with obstructive HCM, but also for improving LV diastolic dysfunction even in patients with non-obstructive $\mathrm{HCM}^{14,15}$ Therefore, it is even more important to predict an increase in DFT before ICD implantation in patients with HCM. Previous studies have described several clinical factors that are associated with a high DFT, such as LV dilatation ${ }^{16}$ body size ${ }^{16}$ decreased LV ejection fraction, ${ }^{17}$ administration of antiarrhythmic drugs (class I; flecainide ${ }^{18}$ mexiletine ${ }^{19,20}$ etc, class III; amiodarone ${ }^{21-23}$ ), myocardial ischemia, ${ }^{24-27}$ the ventricular fibrillation duration ${ }^{28,29}$ and LV mass $23,30,31$ Among these factors possibly associated with high DFTs, only the LV ejection fraction was found to be a univariate predictor of a high DFT in the present study. This might be because HCM exhibits a unique structural and electrophysiologic substrate in the myocardium. Almquist et al reported that extreme LV hypertrophy (wall thickness $>45 \mathrm{~mm}$ ) and the administration of amiodarone were related to a high DFT in patients with HCM 32 The LV mass index was slightly larger in the high than in the low DFT group in spite of the absence of any extreme LV hypertrophy in our series. Although this result was not statistically significant because of the small sample size, this suggests that a larger LV mass might increase the DFT.

\section{QRS Duration and DFT}

Although 2 published studies have shown an association between QRS duration and DFT, QRS duration was not an independent predictor of DFT in multivariate analysis! ${ }^{16,30}$ However, those study populations included mainly ischemic heart disease patients. This is the first study to investigate the association between QRS duration and DFT in patients 
with HCM. Dhingra et al showed that QRS duration was positively related to $\mathrm{LV}$ mass and dimensions in individuals free of heart failure and myocardial infarction $3^{3}$ However, there was no significant association between QRS duration and LV mass in our subjects. Asymmetric LV hypertrophy, which is frequently observed in HCM, might make it difficult to precisely evaluate LV mass in the clinical setting. This might be a possible explanation for our observed data.

\section{Study Limitations}

The results presented here must be viewed as preliminary as they are based on experience in a single center and in a small number of patients. Furthermore, this study was conducted retrospectively. In addition, we did not have any follow-up data on DFT after device implantation. All patients underwent the implantations under general anesthesia using propofol, as described above, which might have elevated the DFT ${ }^{34}$ Thus, it is possible that the DFT in the operating room differed from that in the clinical setting. A further major limitation is the absence of a uniform strategy for the selection of lead systems and antiarrhythmic agents that could affect the DFT. Finally, 2 patients in this study who had unacceptably high DFTs obtained a 10-J safety margin after cessation of antiarrhythmic agents. Moreover, not all patients taking antiarrhythmic agents at the ICD implantation had their DFTs measured after discontinuation of antiarrhythmic agents. We report here that the QRS prolongation was associated with a high DFT at the time of ICD implantation in patients with HCM, leaving doubt as to how much the antiarrhythmic agents would affect high DFT and QRS prolongation. Additional studies in a larger patient population are needed to determine the impact of QRS duration on DFT, as well as the influence of antiarrhythmic agents on DFT, and the long-term consequences of an elevated DFT in HCM patients.

\section{Clinical Implications}

In patients with $\mathrm{HCM}$, the presence of a QRS prolongation on the 12-lead ECG should raise concern about a high DFT at the time of ICD implantation, and those patients should be started at a higher energy level for DFT measurements using a high-output device to obtain an adequate safety margin for defibrillation. In the patients who have already been implanted with an ICD, antiarrhythmic agents, which might cause a high DFT, should be prescribed very carefully. Moreover, when QRS prolongation is present before drug administration, DFT testing is warranted after the initiation of drug therapy.

\section{Conclusion}

The present report revealed an association between the QRS duration and DFT at the time of ICD implantation in patients with $\mathrm{HCM}$. This might provide an important insight into the link between simple 12-lead ECG markers and the energy requirements for successful defibrillation in patients with HCM.

\section{References}

1. Maron BJ, Shen WK, Link MS, Epstein AE, Almquist AK, Daubert $\mathrm{JP}$, et al. Efficacy of implantable cardioverter-defibrillators for the prevention of sudden death in patients with hypertrophic cardiomyopathy. N Engl J Med 2000; 342: 365-373.

2. Maron BJ, Estes NA 3rd, Maron MS, Almquist AK, Link MS, Udelson JE. Primary prevention of sudden death as a novel treatment strategy in hypertrophic cardiomyopathy. Circulation 2003; 107: $2872-2875$.

3. Begley DA, Mohiddin SA, Tripodi D, Winkler JB, Fananapazir L. Efficacy of implantable cardioverter defibrillator therapy for primary and secondary prevention of sudden cardiac death in hypertrophic cardiomyopathy. Pacing Clin Electrophysiol 2003; 26: 1887-1896.

4. Lee CH, Nam GB, Park HG, Kim HY, Park KM, Kim J, et al. Effects of antiarrhythmic drugs on inappropriate shocks in patients with implantable cardioverter defibrillators. Circ J 2008; 72: 102-105.

5. Sherrid MV, Barac I, McKenna WJ, Elliott PM, Dickie S, Chojnowska L, et al. Multicenter study of the efficacy and safety of disopyramide in obstructive hypertrophic cardiomyopathy. $\mathrm{J}$ Am Coll Cardiol 2005; 45: $1251-1258$.

6. Hamada M, Shigematsu Y, Ikeda S, Hara Y, Okayama H, Kodama $\mathrm{K}$, et al. Class Ia antiarrhythmic drug cibenzoline: A new approach to the medical treatment of hypertrophic obstructive cardiomyopathy. Circulation 1997; 96: 1520-1524.

7. Hamada M, Shigematsu Y, Inaba S, Aono J, Ikeda S, Watanabe K, et al. Antiarrhythmic drug cibenzoline attenuates left ventricular pressure gradient and improves transmitral Doppler flow pattern in patients with hypertrophic obstructive cardiomyopathy caused by midventricular obstruction. Circ J 2005; 69: 940-945.

8. Richardson P, McKenna W, Bristow M, Maisch B, Mautner B, O'Connell J, et al. Report of the 1995 World Health Organization/ International Society and Federation of Cardiology Task Force on the Definition and Classification of cardiomyopathies. Circulation 1996; 93: $841-842$.

9. Neuzner J, Liebrich A, Jung J, Himmrich E, Pitschner HF, Winter J, et al. Safety and efficacy of implantable defibrillator therapy with programmed shock energy at twice the augmented step-down defibrillation threshold: Results of the prospective, randomized, multicenter Low-Energy Endotak Trial. Am J Cardiol 1999; 83: 34D-39D.

10. Rashba EJ, Olsovsky MR, Shorofsky SR, Kirk MM, Peters RW, Gold MR. Temporal decline in defibrillation thresholds with an active pectoral lead system. J Am Coll Cardiol 2001; 38: 1150-1155.

11. Sahn DJ, DeMaria A, Kisslo J, Weyman A (the Committee on MMode Standardization of the American Society for Echocardiography). Recommendations regarding quantitation in M-mode echocardiography: Results of a survey of echocardiographic measurements. Circulation 1978; 58: 1072-1083.

12. Devereux RB, Reichek N. Echocardiographic determination of left ventricular mass in man. Anatomic validation of the method. Circulation 1977; 55: 613-618.

13. Babbs CF. Alteration of defibrillation threshold by antiarrhythmic drugs: A theoretical framework. Crit Care Med 1981; 9: 362-363.

14. Hamada M, Shigematsu Y, Hara Y, Suzuki M, Ohtsuka T, Hiasa G, et al. Antiarrhythmic drug, cibenzoline, can directly improve the left ventricular diastolic function in patients with hypertrophic cardiomyopathy. Jpn Circ J 2001; 65: 531-538.

15. Hamada M, Aono J, Ikeda S, Watanabe K, Inaba S, Suzuki J, et al. Effect of intravenous administration of cibenzoline on left ventricular diastolic pressures in patients with hypertrophic cardiomyopathy: Its relationship to transmitral Doppler flow profiles. Circ J 2007; 10: $1540-1544$.

16. Gold MR, Khalighi K, Kavesh NG, Daly B, Peters RW, Shorofsky SR. Clinical predictors of transvenous biphasic defibrillation thresholds. Am J Cardiol 1997; 79: 1623 - 1627.

17. Pinski SL, Vanerio G, Castle LW, Morant VA, Simmons TW, Trohman RG, et al. Patients with a high defibrillation threshold: Clinical characteristics, management, and outcome. Am Heart $J$ 1991; 122: 89-95.

18. Reiffel JA, Coromilas J, Zimmerman JM, Spotnitz HM. Drug-device interactions: Clinical considerations. Pacing Clin Electrophysiol 1985; 8: 369-373.

19. Yoon MS, Han J. Electrophysiologic effects of mexiletine on normal and ischemic ventricles. J Electrocardiol 1982; 15: 109-113.

20. Marinchak RA, Friehling TD, Kline RA, Stohler J, Kowey PR. Effect of antiarrhythmic drugs on defibrillation threshold: Case report of an adverse effect of mexiletine and review of the literature. Pacing Clin Electrophysiol 1988; 11: 7-12.

21. Khalighi K, Daly B, Leino EV, Shorofsky SR, Kavesh NG, Peters $\mathrm{RW}$, et al. Clinical predictors of transvenous defibrillation energy requirements. Am J Cardiol 1997; 79: 150-153.

22. Pelosi F Jr, Oral H, Kim MH, Sticherling C, Horwood L, Knight BP, et al. Effect of chronic amiodarone therapy on defibrillation energy requirements in humans. J Cardiovasc Electrophysiol 2000; 11: $741-743$.

23. Kopp DE, Blakeman BP, Kall JG, Olshansky B, Kinder CA, Wilber DJ. Predictors of defibrillation energy requirements with nonepicardial lead systems. Pacing Clin Electrophysiol 1995; 18: 253-260. 
24. Anastasiou-Nana MI, Tsagalou EP, Charitos C, Siafakas KX, Drakos $\mathrm{S}$, Terrovitis JV, et al. Effects of transient myocardial ischemia on the ventricular defibrillation threshold. Pacing Clin Electrophysiol 2005; 28: $97-101$.

25. Babbs CF, Paris RL, Tacker WA Jr, Bourland JD. Effects of myocardial infarction on catheter defibrillation threshold. Med Instrum 1983; 17: $18-20$.

26. Qin H, Walcott GP, Killingsworth CR, Rollins DL, Smith WM, Ideker $\mathrm{RE}$. Impact of myocardial ischemia and reperfusion on ventricular defibrillation patterns, energy requirements, and detection of recovery. Circulation 2002; 105: 2537-2542.

27. Walcott GP, Killingsworth CR, Smith WM, Ideker RE. Biphasic waveform external defibrillation thresholds for spontaneous ventricular fibrillation secondary to acute ischemia. J Am Coll Cardiol 2002; 39: $359-365$.

28. Strobel JS, Kenknight BH, Rollins DL, Smith WM, Ideker RE. The effects of ventricular fibrillation duration and site of initiation on the defibrillation threshold during early ventricular fibrillation. J Am Coll Cardiol 1998; 32: 521-527.

29. Windecker S, Ideker RE, Plumb VJ, Kay GN, Walcott GP, Epstein AE. The influence of ventricular fibrillation duration on defibrillation efficacy using biphasic waveforms in humans. J Am Coll Cardiol 1999; 33: 33-38.

30. Hodgson DM, Olsovsky MR, Shorofsky SR, Daly B, Gold MR. Clinical predictors of defibrillation thresholds with an active pectoral pulse generator lead system. Pacing Clin Electrophysiol 2002; 25: 408-413.

31. Chapman PD, Sagar KB, Wetherbee JN, Troup PJ. Relationship of left ventricular mass to defibrillation threshold for the implantable defibrillator: A combined clinical and animal study. Am Heart J 1987; 114: $274-278$

32. Almquist AK, Montgomery JV, Haas TS, Maron BJ. Cardioverterdefibrillator implantation in high-risk patients with hypertrophic cardiomyopathy. Heart Rhythm 2005; 2: 814-819.

33. Dhingra R, Ho Nam B, Benjamin EJ, Wang TJ, Larson MG, D'Agostino RB Sr, et al. Cross-sectional relations of electrocardiographic QRS duration to left ventricular dimensions: The Framingham Heart Study. J Am Coll Cardiol 2005; 45: 685-689.

34. Cohen TJ, Chengot T, Quan C, Peller AP. Elevation of defibrillation thresholds with propofol during implantable cardioverter-defibrillator testing. J Invasive Cardiol 2000; 12: $121-123$ 